\title{
É preciso visibilizar as alternativas "silenciadas do Sul": entrevista com a moçambicana Isabel Casimiro
}

\author{
Vera Fátima Gasparetto' 0000-0002-3865-0549
}

'Universidade Federal de Santa Catarina, Programa de Pós-Graduação Interdisciplinar em Ciências Humanas, Florianópolis, SC, Brasil. 88040-900 - ppgich@contato.ufsc.br

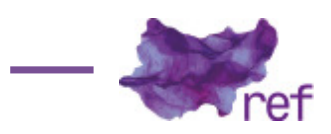

A acadêmica, feminista, e ativista moçambicana Isabel Maria Casimiro é Doutora em Sociologia pela Universidade de Coimbra, professora e pesquisadora no Centro de Estudos Africanos (CEA) da Universidade Eduardo Mondlane (UEM). Atualmente é presidenta do Conselho para o Desenvolvimento da Pesquisa em Ciências Sociais em África (CODESRIA) e coordenadora-geral da Comissão Organizadora do $14^{\circ}$ Congresso Mundos de Mulheres, que será em Maputo, em setembro de 2021. O que nos motivou a realizar a entrevista é contribuir para a circulação do pensamento de intelectuais africanas no Brasil. A primeira entrevista foi realizada no início de 2016 e atualizada em 2019.

Isabel Casimiro dialoga com feministas de várias partes do mundo, as quais contribuíram para sua formação e postura, para além da educação de base. A respeito das organizações feministas, afirma que

há mudanças e permanências. Muitas organizações desapareceram. Hoje se fala abertamente de feminismo e não há receio de se considerar feminista, mas os desafios são enormes devido à falta de fundos e sérios problemas de sustentabilidade, organização e solidariedade dentro e entre organizações. Há problemas sérios de relações de poder dentro das organizações.

Suas vivências políticas como ativista da revolução' e militante dos direitos das mulheres e acadêmica engajada nos feminismos estão expressas nas suas elaborações. Seu trabalho de graduação em História abordou a participação das mulheres na Luta Armada de Libertação Nacional (LALN), e representa um marco do seu interesse pelos movimentos de mulheres e feministas, com os quais continuou trabalhando nos últimos 14 anos.

Sua tese de mestrado em Sociologia (1999) foi orientada pelo sociólogo Boaventura de Sousa Santos e transformada no livro Paz na Terra, Guerra em Casa, ${ }^{2}$ onde ela traça um panorama atual dos movimentos de mulheres e feministas no contexto de Moçambique. A obra foi publicada pela primeira vez em 2004, em Moçambique, e editada no Brasil em 2014, pela Universidade Federal de Pernambuco (UFPE), pela Série Brasil \& África, para a qual a autora escreveu um prefácio atualizando informações sobre a situação geral do país e de algumas organizações de mulheres.

Desde 1980 Isabel Casimiro é pesquisadora do Centro de Estudos Africanos (CEA), da Universidade Eduardo Mondlane (UEM), em Moçambique ${ }^{3}$ tendo criado o Departamento de Estudos da Mulher e Gênero (DEM), em 1990, e o Núcleo de Estudos da Mulher (NEM), em 1988. Foi fundadora da organização não governamental (ONG) regional Women and Law in Southern Africa Research and Education Trust (WLSA), em 1988, e da WLSA Moçambique, 1990, além da Associação Mulher

\footnotetext{
1 Foi integrante da Frente de Libertação de Moçambique (FRELIMO) a partir de 1974, além de exercer mandato parlamentar de deputada, como representante do Partido Frelimo (Frente de Libertação de Moçambique).

${ }^{2}$ Em Moçambique, utiliza-se a denominação tese para dissertação.

${ }^{3}$ Moçambique é um país localizado no sudeste do Continente Africano, banhado pelo Oceano Índico a leste e que faz fronteira com a Tanzânia ao norte; Malawi e Zâmbia a noroeste; Zimbabwe a oeste e Suazilândia e África do Sul a sudoeste.
} 
Lei e Desenvolvimento (MULEIDE) e do Fórum Mulher. ${ }^{4}$ Realizei a entrevista com a autora em janeiro de 2016, para a qual trocamos um conjunto de e-mails.

Na sua tese de Doutorado, intitulada "Cruzando lugares, percorrendo tempos - Mudanças recentes nas relações de género em Angoche", debruça-se sobre as transformações significativas ocorridas no âmbito das famílias na esfera das relações domésticas, a partir de 1950, na África Subsaariana, na África Austral e, sobretudo, em Moçambique. Sua pesquisa tem como referência as investigações realizadas nas últimas três décadas, que evidenciam os processos de tensão e de negociação entre os diferentes membros dos agregados familiares no acesso, controle e partilha de recursos e poder. Foca-se, fundamentalmente, no que diz respeito às relações de gênero e direitos humanos das mulheres, demonstrando que a crise do desenvolvimento em África pode estar também relacionada ao estatuto subordinado das mulheres em relação aos homens, e à perda gradual de direitos sociais, econômicos, políticos e religiosos por parte das mulheres. Tal cenário é resultado das políticas coloniais, do pós-independência e dos programas de reajustamento estrutural promovidos pelo Banco Mundial e Fundo Monetário Internacional (FMI).

Na entrevista é possível conhecer mais sobre o pensamento e a atuação de Isabel Casimiro.

Vera - O contexto de escrita do livro Paz na Terra, Guerra em Casa e o atual são diferentes. Quais as mudanças que você observa nas dinâmicas atuais dos movimentos de mulheres e do feminismo em Moçambique?

Isabel - O livro foi escrito em 1999, apresenta os resultados da minha pesquisa de mestrado, cuja parte letiva havia sido realizada em Coimbra, no Centro de Estudos Sociais, no curso sobre "As sociedades nacionais perante os processos de globalização", em 1996. A discussão se inspira no meu envolvimento anterior nos movimentos de mulheres (OMM, Fórum Mulher, WLSA, MULEIDE) e políticos (fui deputada da Assembleia da República pelo partido Frelimo entre 1995-99, depois das primeiras eleições multipartidárias, em 1994). O curso e debates realizados em Coimbra permitiram-me ressignificar as problemáticas locais e globais no que diz respeito às questões dos movimentos de mulheres, feminismos, ativismos, direitos humanos, relações Sul/Norte e Sul/Sul. Os movimentos feministas influenciados por variados acontecimentos mundiais, a partir de meados do século XX, trazem análises e visões, não novas, mas que revelam a centralidade das mulheres nas opções políticas assumidas. A Frente de Libertação de Moçambique (FRELIMO) "bebe" estas influências, a efervescência é contagiante, desenvolve uma postura de ruptura em relação à participação da mulher na LALN e na revolução. Isso, num contexto contraditório de crítica aos movimentos feministas considerados divisionistas, o que parece paradoxal. Continuo a pensar até hoje que a FRELIMO foi um dos movimentos mais revolucionários no seu tempo, ao ter a coragem de dizer "a participação da mulher é uma necessidade da revolução, garantia da sua continuidade, condição do seu triunfo", na conferência inaugural da Organização da Mulher Moçambicana (OMM), em 1973, em Tunduro, na Tanzânia. E criticar ferozmente os movimentos feministas de onde se originam as posturas mais críticas em relação às variadas opressões das mulheres é bastante problemático e contraditório. Houve muitos avanços nesse processo, mas, como em muitas outras lutas sociais, há, por vezes, nos movimentos esvaziamento dos propósitos revolucionários e emancipadores, muita luta pelo poder, associações que desaparecem por não terem uma postura democrática nas discussões, interferências dos desgastes do dia a dia de trabalho etc. Um aspecto bastante positivo é o Movimento das Jovens Feministas Moçambicanas e a relação entre várias gerações de feministas.

Vera - No livro você historiciza o papel revolucionário das mulheres na luta pela libertação colonial portuguesa. Como essa trajetória impacta no ativismo e na organização atual dos movimentos de mulheres e feministas e no alcance de seus direitos para as mulheres, especialmente no que diz respeito às políticas públicas?

Isabel - Creio que a participação das mulheres na LALN em Moçambique, dirigida pela FRELIMO, constituiu uma importante porta de entrada na luta pelos direitos das mulheres; num contexto de forte influência do patriarcado, de religiões monoteístas patriarcais (cristãs e muçulmana). Mas foi apenas o início, um tempo breve numa longa duração. Há muitos retrocessos hoje, nacionais, regionais e internacionais, apesar das políticas públicas aprovadas por parte de quem participou na luta de libertação; há novas e novos atores e atrizes, com questões diferentes, mas com

\footnotetext{
${ }^{4} \mathrm{O}$ Fórum Mulher é uma rede de organizações e associações femininas, instituições e doadores, com quase uma centena de organizações afiliadas, criado institucionalmente em 1993, com o fim de coordenar atividades de mulheres e outras organizações com o interesse comum de promover a igualdade, a justiça e o aumento do poder real das mulheres em Moçambique.
} 
dificuldades de avanço devido à predominância das forças neoliberais e patriarcais. A nossa chamada de atenção acerca de vários aspectos das políticas é considerada antipatriótica.

Vera - Como as políticas de ajuste estrutural dos organismos multilaterais (FMl e Banco Mundial) se confrontaram com projetos emancipadores e como impactaram na vida das mulheres moçambicanas?

Isabel - Esses organismos "entraram" em Moçambique "pelas mãos" do governo da Frelimo, a partir de 1987, depois do assassinato de Samora Machel (outubro de 1986), mas as negociações se iniciaram ainda na sua direção. E entraram num momento de guerra - seja ela considerada civil ou de desestabilização. Como por todo o lado, foram políticas demolidoras para os projetos emancipadores. Apesar de tudo, aprovou-se uma legislação que permite desafiar a dependência da mulher em vários níveis: a Lei da Família (2003) e a Lei da Violência Doméstica praticada contra a Mulher (2009). Mais uma vez abriram-se portas - devido a pressões internacionais ou internas eleitoralistas - e é preciso mantê-las abertas e continuar a abri-las para outros direitos. A prática desses direitos e políticas tem sido muito difícil e bastante boicotada.

Vera - Você tem uma trajetória militante ligada aos acontecimentos contemporâneos de Moçambique. Como lida com essa experiência entre ser ativista e ser pesquisadora e como a academia vem contribuindo?

Isabel - Tenho lidado bem até agora: a ativista alimenta a académica e pesquisadora que, por seu turno, alimenta a ativista. Desde que dou aulas, em 1975, que estas várias mulheres têm atuado em conjunto e retroalimentando-se. Foi com base na experiência de pesquisa-ação ao nível do Centro de Estudos Africanos (CEA) e da Women and Law in Southern Africa Research and Education Trust (WLSA), e do que ia acontecendo pelo mundo, que iniciamos a introdução de questões de gênero em alguns cursos na Universidade Eduardo Mondlane (UEM). Hoje existe o Centro de Coordenação dos Assuntos de Género (CeCAGe), todo o mundo fala de género e feminismo (ainda que muitas vezes bastante esvaziado dos seus propósitos de mudança), há muita gente entendida e especializada em muita coisa. Mas a entrega, o ativismo, nem sempre estão presentes. Muita atuação existe em troca de dinheiro, apenas.

Vera - Em uma de suas análises você faz uma crítica às "alternativas silenciadas do Sul". Como vê a relação teórica e ativista dentro do campo Sul-Sul?

Isabel - Há muitas alianças Sul/Sul ao nível do continente africano e com organizações da América Latina, Ásia. Há alianças com países do Norte, mas não tem sido fácil. O Secretariado Executivo da Marcha Mundial das Mulheres (MMM) está em Moçambique há vários anos, coordenado por Graça Samo, que foi Diretora Executiva do Fórum Mulher. O seu trabalho tem sido notável e em situações adversas. Aprendemos muito das reflexões e do que se tem produzido pelas feministas no mundo, mas é fundamental partir da nossa realidade e não perder de vista o contexto local, regional e global. Para além de que, Moçambique é um país bastante diverso: cerca de 20 grupos populacionais e linguísticos, mais de uma centena de dialetos, sociedades de filiação matrilinear e patrilinear num contexto patriarcal, muitas religiões, altas taxas de analfabetismo (sobretudo de mulheres), uniões forçadas de meninas (estamos entre os 10 primeiros países no mundo), muita diferença no desenvolvimento do Norte, Centro e Sul do país, áreas urbanas e rurais. E há muitos "Sul", há diferenças enormes no continente Africano e não só. O fato de sermos um país de língua oficial portuguesa afasta-nos de muitos países africanos. Há uma hegemonia dos outros países, sobretudo de língua inglesa. Escrevem-se livros, como, por exemplo, Women and Gender in Southern Africa, e não há qualquer informação sobre Moçambique e Angola. Há anos foi editado um livro sobre mulheres ativistas no continente africano e não havia uma única dos países de língua oficial portuguesa.

Vera - No Brasil existe um debate que propõe superar uma visão linear da teoria de "ondas do feminismo". Essas ondas tiveram influência nos estudos feministas moçambicanos?

Isabel - As referências a ondas ou "vagas" são apenas para abordar as multiplicidades e diversas temporalidades dos feminismos, havendo sempre o receio de encaixar/encerrar demasiado a história em cada uma das ondas. Parece-me que tem muito que ver com as referências a países do Norte ou da América Latina. No caso do nosso país, os processos pela libertação das mulheres estão relacionados com a luta contra o colonialismo português. Há países que ainda nem conseguiram o direito de voto feminino. Parece-me que as ondas ou vagas foram uma forma de abordar as diversas fases, devendo haver a preocupação de ver sempre tudo em perspectiva histórica. Não fomos influenciadxs pelas ondas. As mulheres tiveram direito de voto a partir da independência, a 25 de junho de 1975. Antes, só algumas mulheres de cor branca e com estudos tinham direito a voto em Moçambique. 
Vera - Na sua visão há uma epistemologia feminista africana e moçambicana? Que questões teóricas estão colocadas e como se dão as trocas dentro do continente?

Isabel - Como dizem várias feministas africanas e de todo o mundo, há tantos feminismos quantas as mulheres e as suas lutas contra a discriminação. As discriminações têm aspectos comuns, mas as mulheres são múltiplas e as suas formas de enfrentamento e construção de alternativas também são múltiplas - o que é bastante bom para evitar homogeneizações que não existem. Como referido no livro: A organização DAWN - Development Alternatives with Women for a New Era ${ }^{5}$ considera que existe e deve existir uma variedade de feminismos que responda às diferentes necessidades e preocupações de diversas mulheres, definido por e para elas. Esta diversidade baseia-se numa oposição comum à opressão de gênero e à hierarquia, constituindo-se apenas no primeiro passo para articular e atuar a partir duma agenda política. Neste sentido, e partilhando duma mesma vontade de lutar contra a opressão das mulheres, o movimento foi desenvolvendo tendências diversas em relação à explicação sobre a opressão das mulheres, à sua visão de libertação e ao quadro epistemológico em que se insere. ${ }^{\circ}$

Vera - Numa parte de um dos seus textos você fala de uma sociedade solidária e de respeito pelas diferenças. Do ponto de vista de suas pesquisas atuais, em que medida esse processo avançou na sociedade moçambicana?

Isabel - Avançamos nestes 40 anos, mas há desafios que nos fazem perguntar sempre em que ponto estamos. A verdade é que continuamos, nos últimos 11 anos, com $54 \%$ de pessoas que vivem abaixo da pobreza (sabendo que 1 USD/dia não tem os mesmos significados em todos os contextos), que as relações de poder atuais empurram as pessoas cada vez mais para 0 individualismo, o medo, o reconhecimento da sociedade capitalista como a única, com todo o seu fetiche (o capitalismo tem montras/vitrines muito mais agradáveis). Mais do que nunca e perante a força do neoliberalismo é fundamental encontrar formas de solidariedade inovadoras e que nos abram os olhos para os perigos deste mundo em que vivemos, que nos ofusca e nos põe uns contra outros.

Vera - Qual a importância da realização do $14^{\circ}$ Congresso Mundos de Mulheres em Moçambique para a construção da relação dos feminismos Sul-Sul com os feminismos mundiais?

Isabel - Eu penso que é importante o fato de o MM 2021 se realizar num país do Sul do Sul, pois me parece que há muitos "Sul" nessa relação Sul-Sul, no nosso caso, que é um país de língua oficial portuguesa e que acaba por ficar mais isolado em um mundo que cada vez mais fala inglês e mandarim. É importante porque já estamos deslocadas no contexto dos países do Sul, porque nos situamos no Índico e que fala oficialmente o português. É importante visibilizar as nossas caminhadas, as nossas realizações e desafios. Moçambique foi um dos primeiros países após a independência, em 1975, a realizar pesquisa sobre as mulheres, no contexto de língua oficial portuguesa. O Centro de Estudos Africanos, criado em 1976, teve um papel extremamente importante nesse aspecto. Foi um dos primeiros a fazer pesquisa sobre a luta armada e sobre a participação da mulher na luta armada. Com o projeto WLSA, nós passamos a participar de uma pesquisa regional e como único país de língua portuguesa. Nós quisemos, sem sucesso, envolver Angola. Nós temos, de fato, uma trajetória de muito envolvimento na pesquisa e nos movimentos de mulheres, a partir de 1990, e, anteriormente, na luta armada. No caso da WLSA, nossos relatórios de pesquisa eram escritos em português e em inglês. O Secretariado Internacional da Marcha Mundial das Mulheres está em Moçambique desde 2014, mas quando participamos de encontros internacionais nos sentimos isoladas, nem sempre as pessoas sabem o que estamos a fazer em termos de pesquisa, militância e ativismo. Eu creio que é necessário que a gente possa fazer aqui o MM e mostrar o que é este país, que embora afastado e com características diferentes, mas onde as mulheres das mais diversas formas têm desafiado o capitalismo, o colonialismo e 0 heteropatricarcado. Foi por isso que aceitamos realizar em Moçambique o MM 2021. É um desafio muito grande, pois ainda que tenhamos realizado outros encontros desse calibre, não é fácil pelas características do evento, onde procuramos discutir e realizar as questões coletivamente. Então, se posso resumir, creio que é extremamente importante que o encontro se realize em Moçambique, pois em um contexto de grandes divisões e hierarquias em âmbito internacional, nós somos os países do Sul-Sul e do continente africano. O African Feminist Forum (AFF) existe há mais de 10 anos e na página da web não há nenhuma mulher feminista de Moçambique. Só há a Áurea Mouzinho, de Angola, mas nenhuma de outro país de língua oficial portuguesa - Cabo

\footnotetext{
${ }^{5}$ Mulheres por um Desenvolvimento Alternativo (MUDAR) é um movimento surgido de discussões na Índia, quando dos preparativos para a Conferência das Nações Unidas sobre a Mulher, em 1985, em Nairóbi. O grupo publicou um livro, Development, Crises and Alternative Visions, 1987 (Desenvolvimento, Crise e Visões Alternativas - Perspectiva das Mulheres do Terceiro Mundo (Ed. Gita Sen e Caren Grown)) também editado no Rio de Janeiro, Brasil, alertando os planificadores do desenvolvimento e os políticos para a necessidade de considerar as opressões múltiplas de gênero, classe, raça/etnia e nação.

${ }^{6}$ Conferir em 1.1 O Movimento Feminista, I Capítulo.
} 
Verde, Guiné-Bissau, Moçambique, São Tomé e Príncipe. Ou, então, devemos ser nós a aproximarnos deste Fórum, a fazer-nos presentes, como algumas companheiras têm dito. Há ali várias mulheres que atuam no CODESRIA, mas nós não fazemos parte. Por isso, é preciso visibilizar o que temos feito aqui, quais são nossas realizações e desafios nessas relações Sul-Sul, pois, muitas vezes, há mais aproximação do Atlântico do que do Índico, e é importante mostrar que temos um outro mundo que está para além do Atlântico. E, no caso do continente africano, em que há muitas Áfricas, é importante ver o que uma dessas Áfricas tem estado a fazer, quais são seus sonhos e suas utopias.

\section{Referências}

CASIMIRO, Isabel Maria Cortesão. Cruzando lugares, percorrendo tempos - Mudanças recentes nas relações de género em Angoche. 2008. Tese (Doutoramento em Sociologia na Especialidade de Sociologia do Desenvolvimento e da Transformação Social) - Faculdade de Economia da Universidade de Coimbra, Coimbra, 2008.

CASIMIRO, Isabel Maria Cortesão. Paz na Terra, Guerra em Casa - Feminismos e organizações de mulheres em Moçambique. Pernambuco: EDUFPE, 2014. (Série Brasil \& África - Coleção Pesquisas 1)

FÓRUM MULHER. Disponível em http://ibismozambique.org/parceiros/forum-mulher/. Acesso em 10/ $01 / 2016$.

MOÇAMBIQUE. Disponível em https://pt.wikipedia.org/wiki/Mo\%C3\%A7ambique. Acesso em 10/01/ 2016.

MULEIDE. Disponível em http://www.muleide.org.mz/index.php/a-muleide. Acesso em 10/01/2016.

Vera Fátima Gasparetto (gasparettovera@gmail.com.br) é doutora no Programa de Pós-Graduação Interdisciplinar em Ciências Humanas/UFSC, pós-doutoranda no PPGICH/Área de Estudos de Gênero (Bolsista PNPD/CAPES), pesquisadora do IEG/UFSC, Pesquisadora Associada CEA/UEM. Integrante da Comissão Organizadora do $14^{\circ}$ Congresso Mundos de Mulheres.

\section{COMO CITAR ESSE ARTIGO DE ACORDO COM AS NORMAS DA REVISTA}

GASPARETTO, Vera Fátima. "É preciso visibilizar as alternativas 'silenciadas do Sul': entrevista com a moçambicana Isabel Casimiro". Revista Estudos Feministas, Florianópolis, v. 28, n. 1, e68330, 2020.

\section{CONTRIBUIÇÃO DE AUTORIA}

Não se aplica.

\section{FINANCIAMENTO}

O presente trabalho foi realizado com apoio da Coordenação de Aperfeiçoamento de Print Pessoal de Nível Superior - Brasil (CAPES) - Código de Financiamento 001 e do Programa de Internacionalização PRINT/CAPES.

\section{CONSENTIMENTO DE USO DE IMAGEM}

Não se aplica.

APROVAÇÃO DE COMITÊ DE ÉTICA EM PESQUISA

Não se aplica.

\section{CONFLITO DE INTERESSES}

Não se aplica.

\section{LICENÇA DE USO}

Este artigo está licenciado sob a Licença Creative Commons CC-BY Internacional. Com essa licença você pode compartilhar, adaptar, criar para qualquer fim, desde que atribua a autoria da obra.

HISTÓRICO 